\title{
Intrinsic Relationship with Performance Conscious of Sexy and Latin Dance
}

\author{
Jinfeng Yang \\ Tianjin University of Sport \\ Tianjin,China
}

\begin{abstract}
Latin dance is one kind of the sports collected sports, dance, art. Its comprehensiveness, artistry are strong, and it has rich aesthetic content. It is not only romantic, and full of passion, but also has a vibrant form of artistic expression, loved by the people.
\end{abstract}

\section{Keywords- Latin dance, sexy, relationship}

According to the varied rhythm and rich rhyme, Latin dance is constituted by the combination of point and movement, static point and acting. Its movement has explosive contrast, turning, integrity, and thus gives a unique beauty of moment, process, changes and three-dimension, and an important factor to influence beauty is the expression.

\section{ORIGINATION OF LATIN DANCE}

The origination of Latin Dance is quite complex to trace back, each of its dances originated in different countries, with different backgrounds, history and development process, but most of them are derived from the Americas region, and that they are fusion of three cultures.

Early in the 16th century, in order to get sufficient labor, European conquerors imported a large number of black Africans to the American continent. And in the 17th and 18th centuries, cultures from three continents have been gradually integrated in the American continent. Dance as the main entertainment for the people in the lower class, naturally also fully reflects the integration of this culture, and with the subsequent inflow of European court dance elements, these folk had been further standardized, evolved and improved.

After World War II, Americans will spread these dances around the world, particularly in Europe, it is widely popular. Subsequently, these folk dances and Europeans were standardized and processed, and finally in 1960 the Latin dance was included in worldwide competitions, and is divided into rumba, samba, cha-cha, bull, cowboy. And all aspects such as dance, rhythm, also have a uniform requirement.

Cuba is where Latin dance and Latin music began. Initially, the Latin music and dance was an expression of the harvest to celebrate the victory, then gradually developed a way for young people to each other to express affection. In the course of its development, because the action was too warm, too direct, Latin dance was excluded, but this did not affect the development of Latin dance, irresistible charm make Latin dance popular all over world in the end.

\section{SUMMARY OF LATIN}

There are five kinds of Latin dances: rumba, cha-cha, samba, jive, paso doble. They were originated in different countries and regions, in the early 20th century it became popular in the UK and then in many countries; As a form of social contact, entertainment in the bar is very popular; in the $30^{\text {th }}$ an $40^{\text {th }}$ century, Latin is also very popular in Shanghai. Later, Royal Dance Teachers Association standardized it to become an international event, continues today; One of the more famous British race "Blackpool" Dance Festival (78th), the United Kingdom UK International Championships (51th), British International Open Dance Sport World Championships in Germany.

\section{Cultivate THE EXPRESSIVE FORCE OF LATIN}

\section{A. Professional and technical training}

Latin may use physical body shape training to train athletes' posture. For example, by hand or using a variety of equipment, etc., but also through a combination of some basic movements of ballet and representative dance to train some players and their personality subtly, virtually forming the disposition of elegance. The perfect combination of elegance and graceful movements can better highlight the attributes and expressive force of Latin dance.

Latin dance is in the state of tension throughout the body, there have very strict requirements on the supporting force and elastic force of the legs and feet of the players, as well as waist, back, abdominal muscles relative tight balanced ability and control capacity of arm, shoulder and the entire body. Therefore, training the power of Latin should exercises speed strength, power, etc. to enhance its strength qualities.

\section{B. Music literacy training}

In Latin dance music, rumba is lingering, cha-cha dance is funny, jive is warm, samba is cheerful, paso doble is majestic, each dance has a different way of expression, the selection of music is based on the characteristics of each species dance and their culture to compose, so understanding the cultural style of music is particularly important. Only sufficient knowledge of the music sources can better reflect 
the artistic features of Latin dance, make player completes the best self-expression.

Latin dance and music express the same process, in this process, they complement each other, and training should focus on the players' feeling, understanding and adaptive ability of the music rhythm. Therefore, players should be trained with a variety of styles of music, coaches actively help players understand the rhythm of music and form and style, in order to develop a sense of rhythm and guide and encourage them express themselves with different musical accompaniment, body movements and facial expressions and behave in different ways.

\section{Training The art of dance}

In the competition, player's body movements are generally learn from a variety of dance and re-create, and therefore, in order to have a better body movements, to master dance foundation is a must. Coaches can use basic skills training of ballet to train the body and posture control of the athletes, the use of modern dance training can help players learn how to use body language to express emotions.

\section{Training expression eyes}

When dancing, the two sides have 3 kinds of communication, barycenter, hands, and eyes, the exchange of barycenter here is mainly expressed by way of the body and hands, and eye contact is relatively independent. For example, when the two men face to face dancing, look at each other's eyes, the expression of emotion is needed, especially in the pace of the process of moving, but also to pay attention to eye contact. Eyes training can based on the style of Latin dance itself, with knowledge of other dance and other related projects, learn the necessary skills themselves.

\section{E. Imaginative culture}

Dance is a creative process, with Latin dance music at the time, Lenovo and imagination caused by dance is what we usually say that the association and imagination. Players should learn to strive to be the perception of dance mood and Vivid realm, form their own unique body movements to express language in the process of learning and practice, so that the action expression can be more perfect.

\section{FEATURES 4 LATIN DANCE AESTHETIC ELEMENT ANALYSIS}

\section{A. Latin beauty posture}

Latin dances by dancers' gesture, movement, music, costumes, the performance of various elements of harmony and unity to fully display the charm of Latin dance. Latin dance is an artistic movement, requirements of the ability to demonstrate their artistic charm of the dancers is very high. Researching and studying some of the relevant literature that Latin has some effects on Body shaping, can greatly improve people's body shape in the long term. Correct understanding and awareness of these factors can not only enhance the beauty of Latin dance appreciation level, cultivate people's aesthetic taste, but also to improve the practice effect of dancers fundamentally.

\section{B. Latin dance moves beauty}

Famous British philosopher Francis Bacon said, goodly degree of action is the essence of beauty."While Latin dance movements reflect precisely this beauty, it's every pace, body gestures are made strictly controlled within a certain range. Meanwhile in the beautiful rhythm of the body, and to show people smooth and harmonious action.

\section{Latin dance music aesthetics}

Latin dance music where the soul of its beauty lies, It not only plays an important role in directing and guiding the action of the dancers, its rhythm, and beautiful melodies and distinctive style exhibits rich, moving, subtle, invisible rigid beauty, make art expressive force of Latin stronger. Thus Latin dance music can be the main line of dancers reveals emotions, but also co-infected with the audience into the dance performance situations. The basic means of expression is the melody and rhythm of music. Latin dance music is lively, clear, rhythm strong, passionate, rough mad moving, free-spirited. Different kinds of dance music that reflects different styles, different emotions to mobilize people, For example, considerable charm Rumba Latin music is mildly sweet, and lyrical. Latin is the birth of love magic dance. Many Latin learners in the learning process can easily ignore the music, Latin dance focus only on technical movements' exercises. To some extent Latin dance music determines the motor performance of Latin dance, so the two are one. The image of the perfect combination of dance and music is the highest level of the image of the aesthetic needs of Latin pursue.

\section{Beauty of Latin dance costumes}

Latin tends to show lively, free-spirited atmosphere and flavor of life in Latin America, through flexible dance movements of waist and hip, deliberate pursuit of human motion in curves, to express graceful and gentle performance and dexterity of the ladies. Thus, in the Latin dance costume for male athletes using with a way of "up-tight and downloose," tight-sleeve fitted to the hip pants, create a burly tough, strong side of the styling. Female athletes is more asymmetric lines barelegged style grass skirt, showing off beautiful lines of back, waist, hip, leg movements, and enhance the dance style. As some Latin dance itself is a dance of lover, therefore some ladies apparel also slightly sexy ingredients. Of course, this is fixed in the sexy and elegant taste, both bold design, and carefully dressed, both grand and simple and direct.

\section{E. Beauty of Latin dance performance}

Artistic expression is the highest level of Latin dance. Superb dancing and perfect expression give spirituality and artistic vitality to Latin movement. In other words, the dancers can put inner emotions manifested through physical movements, mainly to see how the power of her performance, and factors that affect the performance and the power of the multi-party. Humanities, arts literacy, movement of skills, 
highly skilled, etc. are the main factors. These expressive qualities can be nurtured overnight, especially the first two factors, need for long repeated practice, exchange, sublimation and gradually formed.

\section{F. Harmony Latin America}

Latin dance is harmonious strong and gentle. Harmony is not only reflected by the dancer from the dance moves to the show's physical beauty, but also by the matching music to reflect. Different dance use different kinds of dance music. This shows a harmonious beauty to a certain extent. They leveraged the force each other, shaped like water, with a common body language to express a variety of rich sense. Harmonious beauty of men and women in dance sport not only refers to their coordinated clothing, figure or movement, but refers to their own aesthetic sense, the creation of aesthetic ideals is a reflection of "the most true, most good," the beauty of male-female relationships in the content. United formal beauty and inner beauty is the perfect combination and is a high degree of unity. In sports dance works, harmonious beauty of men and women on malefemale relationships is by no means simple naturalistic recording and reproduction, but to reveal the nature of malefemale relationships in human society profoundly. From a deeper and broader level, a variety of Latin dance competition promotes cultural exchanges; make a certain contribution on social harmony and stability.

\section{INTRINSICALLY RELATIONSHIP OF SEXY AND LATIN DANCE}

Players' sexy accomplishment is reflecting by Latin dance performance after the rational realization of a sexy theory Latin music. Sexy is created according to the law of beauty, but also in accordance with beauty's law to create their own practice, and also the spirit product created by the players. The essential characteristics are the aesthetic, creative ideology, but also the aesthetic, creative production mode. Latin Dance Players need to have an understanding of form of sports dance. This recognition is achieved by athletes in competitive sports dance as shown by the strong consciousness, thoughts, emotions intent, mood, desire, artistic personality, temperament, artistic style and vocabulary, subjective world of aesthetic delight, aesthetic experience, and create their own appropriate form properly, etc., can penetrate into the dance process, materialize to the desired performance of the dance to reflect.

Dance Sport is the continuity of movement in accordance with certain rhythm. The key elements are posture, structure, movement. Latin Dance is a language of the whole body, is a combination of many factors. Only combined regular, emotional, dramatic, and visual concept of organic organizational factors together, can the players achieve uniform results and enhance sports expressive force of Latin dance.

Now, the Latin dance is an unstoppable craze. No matter its music or dance, Latin styles are popular.

Not only do we want to pursue the beauty of dance, but also to pursue a sexy Latin dance.

\section{REFERENCES}

[1] Mengzhao Xin. Latin Dance artistic ability of professional athletes study [J]. Tianjin Institute of Physical Education,2004,03:66-68.

[2] Xiongwen. Ballroom and Latin dance workout comparative analysis of the value [J]. Physical Institute of Shanxi Normal University, 2007, S1 :20-22.

[3] Tang Ying, Liang Shaoxiong. Study DanceSport amateur artistic expression of [J]. Sport Technology,2009,01:24-28.

[4] Hefen, CheYan Yan. Factors of Discussion Latin expressive and culture [J]. Technological innovation Herald, 2010,17:212.

[5] Liyan. Representation principle applied research [D] for Latin expressive. Hunan University of Science and Technology, 2010.

[6] Li Hongyan, Su changlai. Cultivation of University Students of Latin Dance artistic expression [J]. Big stage,2012,11:228-229.

[7] HE Lin jin. Aesthetic elements of Latin Dance Exploration [J]. Cangzhou Teachers College,2011,01:127-128. 